\title{
Doctors take lead in preparing for assisted dying law
}

I t's unclear how physician-assisted dying will work in Canada when it becomes legal on Feb. 6, 2016, but if national legislation isn't passed, Canada could end up with a patchwork of rules that differs from province to province or even among hospitals.

The Supreme Court's February 2015 ruling gave the government one year to either create laws regulating the act, or leave it to the provinces and medical regulating authorities to develop guidelines. If none of this happens, then hospitals could set institution-specific policies. This could be particularly problematic in a rural hospital where patients have few options but to accept their local institution's ruling.

Federal Justice Minister Peter MacKay announced June 16 that the government needs more time to develop legislation and if the Conservatives are re-elected in the Oct. 19 election, they will ask for an extension. If granted, it would prolong the current situation which was characterized as "cruel" by the Supreme Court in its ruling.

Conservative MP Steven Fletcher, who put forward two private member's bills on physician-assisted death in March 2014, doesn't know when his party will deal with the issue; it could be quite soon, but 'it's also quite possible that there will be no law federally and it'll be up to each province and each hospital to have their own protocols."

In the absence of federal legislation, physician groups foresee the potential pitfalls of piecemeal approaches and are working toward building a framework before the 2016 deadline. The Canadian Medical Forum, composed of 10 medical associations including the Canadian Medical Association (CMA) and the College of Family Physicians of Canada (CFPC), is asking to meet with the ministers of health and of justice, urging them to introduce federal legislation before the deadline. "If we don't have a strong federal framework in place, we would try very hard to have a series of provincial frameworks that are similar," says Dr. Jeff Blackmer, the CMA's vice president of medical professionalism.

The CFPC is also creating guidelines for doctors. "It's important for

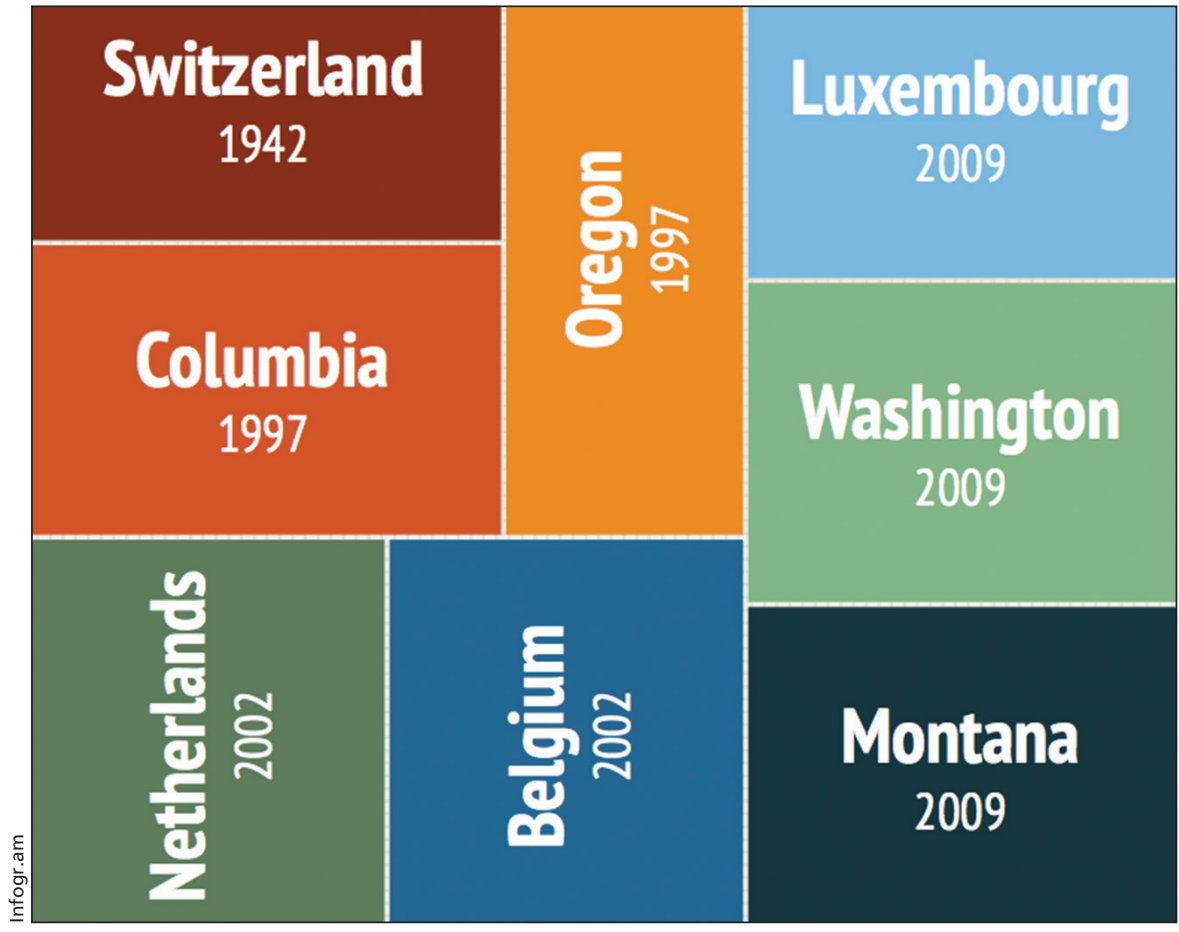

Canada could look to the eight regions that permitted some form of assisted dying as of 2010 to guide its rules.

"physicians to be guided by their conscience. That is quite similar to what we do with abortion," says Executive Director and CEO Dr. Francine Lemire.

And in the event that governments don't want to work with the Canadian Medical Forum, the CMA is also creating a framework. On June 5, it issued a draft version of "Principles-based approach to assisted dying in Canada" to its 80000 members for comment. The document's recommendations include provisos stipulating that advance directives and substitute decision-makers will not be eligible as proxies. Physicians are not obligated to assist in a patient's request to die. CMA aims to finalize the document by late August.

"I'm very confident that the profession as a whole will be able to present a united vision based on the document we've been developing," says Blackmer.

Meanwhile, during the lead-up to the election, Blackmer says the CMA is trying to meet with all political parties on the issue so that when a new government forms in the fall "we won't be starting from scratch."

Not everyone thinks the government needs to come up with legislation. Amir
Attaran, an associate law professor in the Institute of Population Health at the University of Ottawa, says it would be wise for the government to allow the court's decision to stand. "There has to be consent. The person has to be in some serious and irremediable medical condition. What's wrong with leaving it like that?"

But bioethicist and Dalhousie University law professor, Jocelyn Downie, says that without federal or provincial legislation, people are at risk with no procedural safeguards, no ongoing monitoring and unclear policies around access.

Downie says there are already pieces of draft legislation in place that Canada could draw upon. Eight jurisdictions in Europe and the United States have some form of assisted dying. In addition, Quebec passed its own legislation in June 2014 for physician-assisted death, although limited to patients at the end of their life. This legislation is due to come into effect in December 2015. "There are some issues that still require much broader consultation but I fundamentally disagree with the claim that it can't be done on time." - Shannon Lough, CMAJ

CMAJ 2015. DOI:10.1503/cmaj.109-5113 